\title{
Psychodynamic Treatment of Excessive Virtual Reality Environment Use
}

\author{
Lori D. Franklin' and Scott A. Swan²
}

\begin{abstract}
This clinical case study explores the psychodynamic treatment possibilities of excessive Internet virtual reality environment use. The client discussed resides in the virtual world Second Life and experiences her relationships in this environment as more real and meaningful than those in her real life. Instead of focusing on reducing Internet use, therapy conceptualized use of the virtual environment as a compensatory strategy of escapism and conceptualized the relationships and process in a psychodynamic paradigm. This allowed the therapy to address the defenses of splitting and the recapitulation of traumatic events that were evident in the virtual world within an environment that was safer for the client to explore. As a result of accepting the use of the virtual reality environment as an aid to therapy, the client was able to gain insight into her intrapersonal conflicts and eventually bridge the virtual environment to her real life to initiate a trauma-focused therapy.
\end{abstract}

\section{Keywords}

virtual reality, psychodynamic, Internet

When clinicians hear about use of virtual reality video environments, such as Second Life and World of Warcraft, many may make assumptions about the particular pathology associated with excessive use. However, virtual reality video environments appeal to a wide range of people and defy stereotypes of video gamers. According to Castronova and Wagner (2011), more than 10 million users pay a monthly fee to participate in World of Warcraft and up to 12 million or more participate in Second Life, the largest of the online digital worlds. Many of these residents of virtual environments spend so much time in the online world that they come to think of the virtual environment as a more real community than what they experience offline (Castronova \& Wagner, 2011).

Yet excessive use can indicate dissatisfaction with real life. Castronova and Wagner (2011) studied the life satisfaction of Second Life users and found that those with higher life satisfaction were less likely to be intense users. While residency in Second Life is considered different than a usual video game, the literature on problematic gaming indicates excessive Internet use is

'University of Oklahoma, Norman, USA

2University of Tennessee, Knoxville, USA

Corresponding Author:

Lori D. Franklin, Anne and Henry Zarrow School of Social Work, University of Oklahoma, 4502 E. 4 Ist St., Tulsa, OK 74I35, USA.

Email: Ifranklin@ou.edu 
associated with elements of dissatisfaction. A 2009 study of problematic gaming behavior found that $8.5 \%$ of the gamers studied, ages 8 to 18 , endorsed at least 6 of 11 symptoms related to damage to functioning in family, school, or emotions (Gentile, 2009). Those who spend a great deal of time in a virtual environment may do so to escape dissatisfying offline realities. This use of the virtual environment as escapism may appeal to people with particularly painful and difficult lives or those with poor social capacities and a paucity of meaningful relationships. In fact, it may be that excessive use of online virtual reality environments is a compensatory coping strategy for difficult life circumstances as opposed to a disorder itself (Kardefelt-Winther, 2014).

In the context of psychodynamic psychotherapy, this virtual environment may provide rich opportunities as the client recapitulates relationship patterns in the social microcosm of the game and expresses unconscious desires or impulses through the creation and enactment of the avatar. Such opportunities might include identifying corrective social experiences, enhancing relationship building capacities, or using virtual content for the interpretation of real life experiences. This case study explores using the virtual reality environment therapeutically instead of perceiving it as a symptom of a disorder.

\section{Theoretical and Research Basis for Treatment}

The concept of a virtual world presents enormous possibilities for the social sciences. Specific virtual exercises have been utilized in medical and rehabilitation settings and in training environments for students. A great deal of interest has been generated in enhancing prolonged exposure in the treatment of post-traumatic stress disorder through virtual reality representations of combat or terrorist events (Freedman et al., 2010; McLay et al., 2012). These uses of virtual reality create an atmosphere for processing, as well as a tool to facilitate exposure therapy, in line with behaviorally focused treatments (Gonçalves, Pedrozo, Freire Coutinho, Figueira, \& Ventura, 2012). Similar types of in vivo exposure through virtual reality have been utilized for symptoms of panic, agoraphobia, and specific phobias (Riva, 2009) as a way to expose a client to the anxietyprovoking stimulus efficiently and reliably.

Further use of virtual reality has also taken advantage of the social networking possibilities inherent in interactive virtual environments. Second Life has been utilized for weight maintenance programs (Sullivan et al., 2013), and universities have utilized Second Life to enhance courses. These generalized uses of online environments call into question the stereotypes of those who utilize them. In fact, researchers studying problematic video game use (Mentzoni et al., 2011) found that while $56 \%$ of their sample played video games, only $4 \%$ met criteria for excessive or compulsive gaming. A higher risk of problematic gaming was found in younger male respondents reporting higher anxiety or depression and lower satisfaction with life. Furthermore, a study in the United Kingdom (Collins, Freeman, \& Chamarro-Premuzic, 2012) found that problematic MMORPG (massively multiplayer online role-play game) play was correlated negatively with agreeableness and impulse regulation but did not correlate with openness, emotional intelligence, or extraversion, as expected. Demographically, 50\% of MMORPG residents have full-time employment, $36 \%$ are married, and 22\% have children. Residents spend on average 22 $\mathrm{hr}$ a week in the virtual environment (noting that Nielsen, 2012, reports that Americans spend on average $27 \mathrm{hr}$ a week watching TV), while $80 \%$ report engaging simultaneously with someone they know in real life (Yee, 2006a).

While video gamers are often stereotyped, Yee (2006b) found that there are multiple reasons why a person might choose to engage in role-playing environments. Reasons include (a) achievement components including a desire to gain power, analyze systems, and compete with others; (b) social components including socialization, relationship building, and teamwork; and (c) immersion components including enjoyment of role-play and customizing the characters, as well as escapism. Of particular interest is the gendering of these subcomponents, whereas female 
players score significantly higher than males on the relationship subcomponent although both genders score highly on the socialization component (Yee, 2006b). The implication is that women who utilize role-playing environments are searching for meaningful relationships that may either supplement, substitute for, or lead to real life relationships. Significant interactions offline may occur, with up to $72 \%$ of participants communicating outside of Second Life (Gilbert, Murphy, \& Clementina Ávalos, 2011). Age was also associated with escapism, indicating that, as burdens and responsibilities increase with age, participants are more in need of escape (Park, Song, \& Teng, 2011). In the general population, age is not associated with a decrease in life satisfaction (McAdams, Lucas, \& Donnellan, 2012), so this finding implies that older residents may be experiencing a higher than average dissatisfaction with real life and a subsequent need to engage in escapism.

Second Life is uniquely suited to the exploration of relationships as the avatars engage in relatively life-like pursuits. For a resident with borderline personality disorder, with its characteristic dysregulation of affect, behavior, and relationships, the relationships experienced in Second Life will also likely be chaotic. The splitting or dichotomous thinking that is a core feature of this disorder, resulting in split cognitive representations of persons or experiences (Coifman, Rafaeli, Berenson, \& Downey, 2012), could lead to polarized fluctuations between negative and positive relationship experiences online, possible impulsive online behavior such as aggressive dialogue or abrupt avatar alterations, or even the creation of multiple avatars to symbolize the many internal representations of self that the resident holds. In short, the online behavior is likely to mimic real life behavior, but perhaps with even less inhibition and more aggression due to the shield from real life consequences.

Intense users of online environments are likely to be categorized as clients with "Internet addiction" and are typically treated with a cognitive behavioral model (Kim, Han, Lee, \& Renshaw, 2012; Rooij, Zinn, Schoenmakers, \& Mheen, 2012; Young, 2011). However, consideration of the type of Internet use and the potential interpersonal deficits addressed through the online experience is important. Treating an adolescent who plays a violent, war-inspired game is a different matter than treating a middle-aged woman who intensely uses a life-like role-playing environment to establish relationships she sorely lacks. The virtual reality environment is a potentially rich one for practicing new skills and experimenting with affect regulation before trying on those skills in a riskier real life environment. The outcomes of practice and experimentation could be seen in Second Life and then gradually extrapolated to real life. In addition, the potential for interpretation of the symbolic nature of role-play is enormous. A psychodynamic therapist could maximize the impact of therapy by offering interpretations relating both to the real life identity, as well as the projections of self-represented by the avatar. Therapeutic work would become dually focused on the real and the fantasy self, integrating both of the split selves by building insight and skill development in a ready-made in vivo environment.

The online virtual environment presents interesting opportunities for psychodynamic psychotherapy, especially with a client who is searching for ways to enhance meaningful relationships and escape painful realities of life. Although not meant to imply an association between a personality disorder and an interest in online role-playing environments, a client with both borderline personality disorder and an interest in Second Life may be likely to search for meaningful relationships online when finding relationships dissatisfying in real life. The case description below concerns a middle-aged woman with underdeveloped social skills and few real life relationships, which are potentially abusive and, at best, dissatisfying. She has been diagnosed with borderline personality disorder, as well as major depressive disorder.

\section{Case Introduction}

Brenda, a 54-year-old Caucasian woman, was referred to treatment by her primary care physician. Notable on the first session was her unkempt appearance and flat affect. She reported 
depression symptoms including difficulty in finding motivation to shower or attend to personal hygiene. She gave one word answers to initial questions, looking down at her lap. Her medical record included diagnoses of major depressive disorder, severe without psychotic features, and borderline personality disorder. She also experienced medical complications including hypertension, type 2 diabetes, and nicotine dependence.

\section{Presenting Complaints}

Significant symptoms of depression reported by Brenda were very irregular sleeping habits and difficulty with sleep, a severe lack of motivation including being unable to take a shower or take out trash, and great difficulty leaving her apartment for appointments. She stated vaguely that the virtual reality environment, Second Life, was the one thing that kept her from being suicidal. Her mood was very sad and she could think of nothing about herself that she liked. The client lived with a man, Gavin, about whom she stated, "He's my boyfriend, and he's abusive to me when he drinks, but I don't want to do anything about that. We keep to ourselves and I couldn't afford to live on my own." This statement was said as a matter of fact, though with a clear underlying message that this topic was not to be approached and an assertion that she would control that part of our therapy.

\section{History}

Brenda grew up in a rural Midwestern town with both parents and two siblings. She did not complete high school and her employment as an adult had been sporadic, mostly consisting of small jobs online. She was receiving Supplemental Security Income (SSI) for the disability of depression. She stated that she had one suicide attempt in her young adulthood, but none since. She had been married briefly, was divorced, and had no children. When asked about any history of physical or sexual abuse, she stated, "All that [numerous incidents of sexual abuse] happened, but I do not want to talk about it. My last therapist just wanted to bring that up every time, so I quit." She clarified to state that she had been molested by multiple perpetrators through her life span and raped by two men before the age of 10 . I explained at this point that there may be a need to talk about the abuse in the future if we feel it is a core issue to address, but said that I would not focus on it if she was not ready to do so. This acknowledgment seemed to go a great distance toward building rapport and lessen the aggressive way in which she was asserting the frame of therapy topics.

Brenda went on to describe a great paucity of relationships. Her relationship with Gavin was distant and polite at best, much like roommates, but when he was drinking, he expected sex, which was rough and painful for her, and she felt unable to stop it. He was verbally abusive at these times, and her strategy was just to be silent and wait for him to become sober. She reported one friend to whom she occasionally spoke on the phone, but she was unwilling to let this friend into her home due to shame about her home's condition. She also stated that she and the friend had disputes about Brenda's relationships in Second Life, which they both play.

When asked how she spends her time, Brenda began to talk about Second Life, disclosing that she is literally in Second Life all the time. She initially phrased her statement sheepishly, seeming to expect disapproval for spending this amount of time online. However, when asked follow-up questions about the virtual environment, her affect brightened slightly, her posture relaxed, and she began to look forward instead of down. She described her character in the environment, Freesia, as beautiful and smart, a woman who loves to dance and have fun, adding that men love her. In Second Life, Freesia had a husband, Snake, and an infant daughter. Brenda described a loving family that spent time together and stated, "Freesia is everything I have ever wanted to be and I would rather live my life through her than as my real self." However, she voiced some 
concerns about Snake's faithfulness and some conflicts experienced over care of the virtual infant.

\section{Assessment}

Brenda completed a psychosocial assessment both with a clinical social worker and with a psychiatrist. She was assessed for depression through the Beck Depression Inventory and scored a 33 , indicating severe depression. Although she mentioned a history of trauma, she declined to complete trauma assessment instruments due to her lack of interest in discussing those therapeutic issues.

When asked about goals she wished to set in treatment, she did not wish to reduce use of her computer. She did wish to feel less anxiety about leaving her home, as evidenced by not canceling appointments due to anxiety. She additionally wished to be able to motivate herself to shower before she attended her appointments with the therapist.

\section{Case Conceptualization}

Having little experience with what seemed like excessive use of the Internet, my initial reaction to Brenda was concern about Internet "addiction" and the great amount of time she spent online. I was concerned that she would be hindered from working on meaningful relationships and gaining satisfying experiences in her real life if she remained so consumed with virtual reality. My first impulse was to implement a cognitive behavioral therapy (CBT) intervention focused on reducing intrusive thoughts of engaging in Second Life and on a gradual reduction of hours spent online; but, I was well aware that suggesting this would not be well received and perhaps was not even advisable given her statement that Second Life was what kept her from feeling suicidal. Literature questioned the concept of "addiction" as applied to the problem of excessive gaming (Essig, 2012), and I found that an explanation of addiction seemed ill-fitted for conceptualizing Brenda's case. Instead, a more meaningful conceptualization was found in the Kardefelt-Winther (2014) study of compensatory Internet use, which viewed the motivation as escapism from complex life problems. Although this study utilized data from a different MMORPG, World of Warcraft, the idea of excessive virtual environment use as a coping strategy instead of a disorder seemed promising (Kardefelt-Winther, 2014). Brenda had clearly been using the virtual environment as a method of managing her dissatisfaction with her real life by living as if she were another person, Freesia. Dismantling these defenses before she had developed an adaptive replacement seemed unwise. Even if I had attempted to do so, clearly Brenda would have terminated therapy immediately had I suggested reducing the use of Second Life as a treatment goal, which was obviously my goal and emphatically not hers.

Being diagnosed with borderline personality disorder, as defined by the Diagnostic and Statistical Manual of Mental Disorders (5th ed.; DSM-5; American Psychiatric Association, 2013), Brenda presented a much more complex clinical picture than easily explained by the $D S M$. Her descriptions of her online persona seemed at times stable but were also characterized by affective lability, intense emotion, and outbursts of aggression triggered by disruptions in what appeared to be a dependent relationship with Snake. Freesia would erupt with anger at Snake, threaten him, threaten suicide, refuse to allow him to see their child, or spend long periods of time refusing to speak to him. Freesia seemed to display an anaclitic type of borderline personality organization congruent with the DSM description (Psychodynamic Diagnostic Manual [PDM] Task Force, 2006).

However, as she sat before me, Brenda was withdrawn and socially deficient, socially isolated, and lacking in motivation to pursue relationships, as well as arguably obsessive about her use of Second Life. This presentation was more consistent with the introjective type of borderline 
personality organization that often more aligned with the DSM diagnosis of schizoid personality disorder (PDM Task Force, 2006). Brenda was suffering from such severe interpersonal deficits in her real life, due most likely to profound childhood abuse experiences and the insecure attachment that resulted, that she had found a safer environment online in which to search for meaningful relationships. Her lapses into referring to the virtual environment in present tense, Freesia as a separate person, and the baby as living suggested an intense difficulty in maintaining a present orientation, as she seemed to waiver between aspects of psychotic lapses and neurotic functioning. Her defenses in the virtual environment were noticeably intricate and well developed, protecting her from brutal real life circumstances.

Clearly present in Freesia was the defense of splitting. She spoke of Snake in an exaggerated and complimentary fashion, noting her encompassing love for him, his attentiveness as a husband and father, and his devotion to her as unwavering. Later sessions would prove that her perception of Snake would eventually become unrealistically negative; yet, even from initial meetings, her descriptions of Snake were undoubtedly overly idealized and most likely a product of splitting. This was in contrast to Brenda herself, who characterized her relationship with Gavin as one of chronic unhappiness, along with an apathetic acceptance of that relationship as being unchanging.

Brenda was fully aware that Freesia was not literally real, but her identification with Freesia seemed somewhat dissociative, as if she were so identified with the character that it actually felt more real than her depersonalized feelings about her real life. This indicated a profound intrapersonal conflict, possibly rooted in her early trauma experiences, but clearly resulting in maladaptive defenses that manifested in Freesia's poor affect regulation and Brenda's restricted affect. Her relationships seemed stunted and ridden with anxiety, in both the virtual and real life contexts. Moreover, her relationship with Gavin was characterized by avoidance and a blunt affect, whereas her relationship with Snake was characterized by lability and poorly controlled emotional expression.

To conceptualize treatment, the first focus was on the most prominent relationship in her life: her relationship with Snake. While Snake represented any number of splits, I focused first on her relationship with him in the context of the virtual environment and the skills that Brenda had used as Freesia, which indicated Brenda's inherent capacity for the resolution of interpersonal conflicts. My hope was that, by building her sense of efficacy in relationships in the virtual world, she could internalize relatively adaptive characteristics of Freesia, eventually translating those to her life as Brenda. If we gained sufficient rapport for me to make these connections, these comparatively adaptive defenses could help resolve the impasse in her relationship with Gavin and potentially allow her to grieve what I wondered might be a sense of loss at not having a child of her own. My goal became to support the adaptive defenses, while also trying to help her integrate her online self with her real self, by highlighting the admirable qualities in Freesia that I also observed in Brenda.

\section{Course of Treatment and Assessment of Progress}

\section{Initial Sessions}

During initial sessions, we completed a psychosocial assessment and reviewed the symptoms of depression. I explained major depressive disorder and the ways in which she met criteria including depressed mood, diminished interest in activities, sleep disturbance, psychomotor retardation, fatigue, feelings of worthlessness, and thoughts of death. She agreed that she was depressed and seemed comfortable acknowledging this diagnosis.

I also explained that, while I fully understood that she did not wish to discuss it in therapy at this time, she should be aware that many adults who have experienced childhood sexual abuse 
often have feelings of depression, difficulty with relationships, and disturbing memories and thoughts about the abuse. I elaborated her childhood trauma had possibly disrupted her ability to form healthy attachments with others, created maladaptive defenses to conflict, and this could explain a number of her problems. I phrased this as a simple explanation without inviting her to expand on the topic. She indicated that this explanation made sense to her.

We then further discussed both her real life and virtual relationships. Although clearly her problems began in childhood as a result of abuse, she identifies her relationship with Gavin as significant in her depression history. She felt used by Gavin from the beginning, unloved and unappreciated, but was simultaneously convinced that she was unworthy of a more satisfying relationship. She felt obligated to be used sexually, while deserving of abuse, likely in a repetition of her past trauma. She did not seem to expect that the abuse would end, nor that it would result in any different or better outcomes for her. This masochistic part of her self seemed unwelcome but accepted. Over initial sessions, however, she was able to examine the feelings of loneliness, the increasing feelings of worthlessness, and the sadness that accompanied feeling trapped with Gavin.

She was more focused, though, on her relationship with Snake. She was concerned that he was meeting other women in Second Life as his avatar was attractive and charismatic. Although she had neither met nor seen him in real life, she had given him her cell phone number, and they called and texted repeatedly. They had arguments, both online and through the cell phone, about him staying out late, not spending time with Freesia and the baby, and neglecting to buy them the virtual credits necessary for diapers, food, and clothing. She also harbored strong suspicions about his interactions with other female characters.

Within the potential space of this virtual environment, these interactions can be conceptualized in multiple ways. On one hand, they can be seen as manifestations of relationships for which Brenda longs, such that she can have a better partner and a child to nurture in this other world. On the other hand, Snake and the baby could also be understood as representations of both her own child-like self and a wilder more phallic-narcissistic self that dates openly, indulges in carnal or exhibitionist behavior, and lives carefree. Regardless of the psychodynamic implications of her online persona and relationships, this relationship was plainly very real to Brenda, and the relationship with Snake was the most significant one in her life.

Initial goal setting focused on enhancement of adaptive defenses in the context of managing relationship conflict. Brenda stated that she would like for Freesia to be able to confront Snake assertively without a verbal fight and enhance their communication overall as a couple. Although my concern was more about the relationship with Gavin, she was initially hesitant to set a goal about improving the relationship with him. I was content with first focusing on Freesia and Snake with hope that the insight would extrapolate to her real life relationship.

\section{Intermediate Sessions}

Subsequent sessions continued to focus on the relationship with Snake, not Gavin. Brenda's relationship with Gavin was at an impasse; the relationship was mostly silent and apathetic, avoiding contact, and characterized by low-level resentment. Although conflict occasionally escalated, either by Gavin's drinking or other factors, the relationship did not appear to be in danger of dissolution at this time, as it seemed to be a pattern that had existed without disruption. Whenever the subject of the relationship with Gavin was approached, Brenda abruptly stated that, for financial reasons, there could be no option of dissolving the relationship. Her posture and affect would then immediately close.

Freesia's relationship with Snake, however, was in a stage of renegotiation. They were actively, verbally arguing and both seemed to be trying to please the other through changes in behavior. Freesia planned family activities and date nights to try to interest Snake in being at their 
Second Life home. Snake appeared to sometimes respond and sometimes not. Sessions were spent rehashing the conversations with Snake and I noted that her communication was very direct and assertive with him, drastically different than her passivity with Gavin in real life. I pointed this out to her, as well as noted that her communication with me, especially in terms of what topics were fair game for discussion in session, was also very confident and showed an ability to exert control over her environment.

While the drama with Snake was escalating as she became more certain that he was having sexual relationships with other avatars, her sense of Freesia's self-worth was remarkable. She was unwilling to allow Freesia to be taken advantage of and her baby not cared for properly. Although indicating poor affect control, Freesia would confront Snake, offer ultimatums, and engage in heated arguments that were a far cry from the passive withdrawing and regressing she described in her real life relationships. I continued to point out examples of adaptive defenses, such as expressing her anger without overreacting and asserting her differences in expectations of the relationship. She made progress in controlling her impulses; initially, she would threaten to impulsively kill Freesia's character and start over with a new avatar but would mourn these ideas and decide to continue the relationship to a solution. She displayed a tenderness, possibly maternal, toward Freesia that made her unable to fathom harming her in that way.

As I supported these strengths in adaptive defenses, I tentatively asked her to compare Freesia with Brenda. I wondered why Freesia was able to harness the strength to confront a man who is mistreating her, when Brenda feels paralyzed and unable to affect her situation with Gavin. This conversation may have been premature, as she focused on her need to maintain the relationship with Gavin for financial reasons and felt she was at risk if she were to "rock the boat." She identified though that Freesia was beautiful, fun, and desirable in ways that Brenda felt she was not, implying that Freesia, therefore, deserved better treatment. Her attention turned to self-criticism and expressions of disgust with her physical appearance.

Eventually, the relationship with Snake escalated further. During one session, he called repeatedly. Brenda's flip phone was on vibrate and she would just snap it open and shut each time he called until I asked her to turn it off. Finally, he "kidnapped" the baby and left Freesia for another woman. Freesia tried desperately to convince him to return, fought fiercely for him to return the baby and not raise the baby with another woman, but eventually accepted that the relationship was dissolved. A couple of sessions were devoted to grieving the loss of the relationship but highlighting the assertive and self-respectful behavior that Freesia exhibited.

Interestingly, this crisis led to disclosure about other failed intimate relationships Brenda had experienced. She had previously met men online and interacted with them but had struggled with their requests for a real life picture. She had experienced some humiliation in response to pictures she had sent before and now felt she could only experience intimacy by hiding behind her virtual character. She made disparaging comments about her appearance and indicated she had given up on trying to improve her appearance or attend to hygiene. I reflected with Brenda on the symbiotic relationship between depression and hygiene and how difficult it becomes to care about appearance and motivate ourselves to address it when depressed. I proposed to her that perhaps her poor hygiene lessens the frequency of Gavin's unwanted sexual contact, leading her to either directly or subconsciously neglect her personal care. She agreed and acknowledged that her poor hygiene also keeps others that she might wish to build relationships with away from her as well.

\section{Complicating Factors}

A significant complication was Brenda's tendencies toward agoraphobia. She frequently canceled appointments or would call in tears hoping for a telephone session and, at times, seemed frustrated that I asked her to reschedule a face to face appointment if she was unable to attend. She would often not show up for appointments and then call later to reschedule with mild irritation that I could not see her again for up to 2 weeks. 


\section{Access and Barriers to Care}

Brenda is a client without insurance who is seen at a community medical clinic that is a training facility. She has transportation difficulties and relies on Gavin's generosity of letting her use his truck to drive to appointments. In addition, she has health concerns including poorly controlled diabetes, which results in medical complications.

\section{Follow-Up}

There was a change in Brenda's hygiene through the treatment process. Her clothes appeared cleaner, her hair appeared washed more often, and she did not have body odor. She briefly summarized some continuing drama with Snake but overall had succeeded in remaining separated. She was able to discuss additional relationships she had begun to create in the virtual environment as Freesia, both with male and female friends, and seemed to be enjoying meeting new people. She grieved the relationship with Snake, stating he was the only man she had ever loved, but she realized he did not feel the same way about her. I helped Brenda note that she survived Freesia's breakup, that Freesia has the capacity to live on her own within Second Life without a relationship, and proposed that perhaps Brenda herself is more capable of doing so in real life than she might think.

On a very positive note, Brenda discussed a phone conversation she had with a real life friend who also engaged in Second Life. She had seen her friend online, and the friend discovered that Freesia and Snake had broken up. The friend had disapproved of the relationship and had distanced herself from both Freesia and Brenda. She was now, however, a possible support for Brenda during the breakup.

Brenda was still with Gavin but could relate some minor instances of increasing her assertiveness and expressing her needs to him in a way that avoided maladaptive defenses, especially in terms of when she needed the truck to attend her appointments. She also had begun leaving her home more to see her friend when she knows he has been drinking. Although these are not tremendous gains, and I remain fearful for Brenda's safety, they do show a gradual integration of ability to resolve interpersonal conflict in a way that avoids regression or isolation into schizoid type pathology.

Brenda was very close with her elderly dog, which was a great source of comfort to her. The dog died during the course of treatment and Brenda's symptoms escalated as she mourned this profound loss. However, the decline and death of the dog actually worked to help her shift her focus away from the virtual environment exclusively and allowed her to be grounded in the responsibilities of her real life as she cared for her pet. So, while her symptoms escalated, she also took assertive action to have her medication re-evaluated and was able to withstand the crisis admirably.

Her scores on the Beck Depression Inventory spiked in the middle of treatment, and then eventually, her scores decreased to lower than when she initiated treatment. The spike in scores was most likely due to the tension of treatment, the crisis of escalating conflict with Snake, and the death of the dog. But these scores eventually stabilized and lowered once her medications were adjusted and the effects of her gradual integration of adaptive behavior increased.

The final session with Brenda, however, was remarkable. She appeared at the session stating that she had composed a letter for me to read. It was a trauma narrative that described her first sexual assault in her childhood. This was a turning point for therapy, as she had not only reached a point where she was ready to address her traumatic history but was also able to assertively direct therapy to a trauma-focused model. This marked an ending of this psychodynamic exploratory stage of therapy, and therapy could now shift to a trauma-focused intervention such as cognitive processing therapy. 


\section{I Treatment Implications of the Case}

This case widens the view of treatment of "Internet addiction" and expands the repertoire of interventions available for the treatment of Internet users. In addition, this case encourages more specificity in considering the motivation, benefit, and therapeutic usefulness of online environments, understanding that a person who utilizes a realistic online environment might be different than someone who engages in online fantasy role-play, a competitive game, or a violent video game.

Most importantly, this case encourages viewing the creation of avatars and behavior in online relationships from a psychodynamic lens. Especially for clients with characterological or personality disorders, the creation of an online persona has important symbolic and psychodynamic meaning that creates potential for interpretations that can bridge to real life.

The case exemplifies the need for thoughtfulness around interpretive timing and dosage when working with such fantasy relationships and their defensive function. Early acknowledgment of the valid usefulness and personally identified nature of such interactions would likely strengthen the therapeutic relationship and build opportunities for thematic analysis. As a client becomes increasingly comfortable with exploring online relationships and parts of self in therapy, the opportunity for clarifying interpersonal dynamics that resonate with other relationships and one's broader sense of self should grow proportionately. The client's level of comfort and emotional insight when making such connections may signal readiness to process the defensive function of the fantasy relationships themselves, or their setting and context. Subsequently, this insight can guide the development of increasingly diverse and healthy defenses that serve a similar function. However, abrupt debate or disregard for such relationships and aspects of self that are deeply meaningful to the client would likely disenfranchise them or lead to client-initiated termination.

\section{2 Recommendations to Clinicians and Students}

When presented with a case of this nature, to proceed with the originally considered intervention of CBT related to reducing Brenda's use of Second Life would have been easy but, also, a fatal mistake to treatment. In addition, initiation of a trauma-focused model of treatment at the time of Brenda's presentation would have likely been ineffective. Instead, clinicians must acknowledge the significance of the online experience for the client and explore it as a meaningful part of the client's social environment. Accepting the significance of Second Life became a part of starting where the client is and working with her in the context of her environment. She had established her residence there as a safe place to explore new behaviors and ideas, much like the therapeutic environment can be under the right circumstances. Failure to utilize that safe environment to help build a bridge to the therapeutic experience would have greatly inhibited any chance of success at helping her learn to negotiate real life experiences that were profoundly unsafe for her to explore right away in therapy.

In addition, students and clinicians need to validate the realism and importance of Second Life, not only as a realistic environment of great meaning but also as a potential display of psychodynamic symbolism. Brenda's creation of an idealized online child that she struggled to protect, her repetitive recapitulations of an abusive relationship even when she tried to create an idealized family, and her in vivo practice with adaptive defenses and balancing of polarized affect in her arguments with her online husband all had significant therapeutic meaning. These dynamics would not have been obvious if the therapy had focused purely on her real life relationship.

\section{Declaration of Conflicting Interests}

The author(s) declared no potential conflicts of interest with respect to the research, authorship, and/or publication of this article. 


\section{Funding}

The author(s) received no financial support for the research, authorship, and/or publication of this article.

\section{References}

American Psychiatric Association. (2013). Diagnostic and statistical manual of mental disorders (5th ed.). Arlington, VA: American Psychiatric Publishing.

Castronova, E., \& Wagner, G. G. (2011). Virtual life satisfaction. Kyklos, 64, 313-328. doi:10.1111/j.14676435.2011.00508.x

Coifman, K. G., Rafaeli, E., Berenson, K. R., \& Downey, G. (2012). From negative to positive and back again: Polarized affective and relational experience in borderline personality disorder. Journal of Abnormal Psychology, 121, 668-679. doi:10.1037/a0028502

Collins, E., Freeman, J., \& Chamarro-Premuzic, T. (2012). Personality traits associated with problematic and non-problematic massively multiplayer online role playing game use. Personality and Individual Differences, 52, 133-138. doi:10.1016/j.paid.2011.09.015

Essig, T. (2012). The addiction concept and technology: Diagnosis, metaphor, or something else? A psychodynamic point of view. Journal of Clinical Psychology, 68, 1175-1184. doi:10.1002/jclp.21917

Freedman, S. A., Hoffman, H. G., Garcia-Palacios, A., Weiss, P. L., Avitzour, S., \& Josman, N. (2010). Prolonged exposure and virtual reality-enhanced imaginal exposure for PTSD following a terrorist bulldozer attack: A case study. CyberPsychology, Behavior, and Social Networking, 13, 95-101. doi:10.1089/cyber.2009.0271

Gentile, D. (2009). Pathological video-game use among youth ages 8 to 18: A national study. Psychological Science, 20, 594-602. doi:10.1111/j.1467-9280.2009.02340.x

Gilbert, R. L., Murphy, N. A., \& Clementina Ávalos, M. (2011). Realism, idealization, and potential negative impact of 3d virtual relationships. Computers in Human Behavior, 27, 2039-2046. doi:10.1016/j. chb.2011.05.011

Gonçalves, R., Pedrozo, A. L., Freire Coutinho, E. S., Figueira, I., \& Ventura, P. (2012). Efficacy of virtual reality exposure therapy in the treatment of PTSD: A systematic review. PLOS ONE, 7(12), 1-7. doi:10.1371/journal.pone.0048469

Kardefelt-Winther, D. (2014). The moderating role of psychosocial well-being on the relationship between escapism and excessive online gaming. Computers in Human Behavior, 38, 68-74. doi:10.1016/j. chb.2014.05.020

Kim, S. M., Han, D. H., Lee, Y. S., \& Renshaw, P. F. (2012). Combined cognitive behavioral therapy and bupropion for the treatment of problematic on-line game play in adolescents with major depressive disorder. Computers in Human Behavior, 28, 1954-1959. doi:10.1016/j.chb.2012.05.015

McAdams, K., Lucas, R., \& Donnellan, M. (2012). The role of domain satisfaction in explaining the paradoxical association between life satisfaction and age. Social Indicators Research, 109, 295-303. doi:10.1007/s11205-011-9903-9

McLay, R. N., Graap, K., Spira, J., Perlman, K., Johnston, S., Rothbaum, B. O., . . Rizzo, A. (2012). Development and testing of virtual reality exposure therapy for post-traumatic stress disorder in active duty service members who served in Iraq and Afghanistan. Military Medicine, 177, 635-642.

Mentzoni, R. A., Brunborg, G. S., Molde, H., Myrseth, H., Skouverøe, K. J. M., Hetland, J., \& Pallesen, S. (2011). Problematic video game use: Estimated prevalence and associations with mental and physical health. CyberPsychology, Behavior, and Social Networking, 14, 591-596. doi:10.1089/ cyber. 2010.0260

Nielsen Company. (2012). The Cross-platform report: Quarter 4, 2011 - US. Retrieved from http://www. nielsen.com/us/en/reports/2012/the-cross-platform-report-q4-2011.html

Park, J., Song, Y., \& Teng, C.-I. (2011). Exploring the links between personality traits and motivations to play online games. CyberPsychology, Behavior, and Social Networking, 14, 747-751. doi:10.1089/ cyber. 2010.0502

Psychodynamic Diagnostic Manual Task Force. (2006). Psychodynamic diagnostic manual. Silver Spring, MD: Alliance of Psychoanalytic Organizations.

Riva, G. (2009). Virtual reality: An experiential tool for clinical psychology. British Journal of Guidance \& Counselling, 37, 337-345. doi:10.1080/03069880902957056 
Rooij, A., Zinn, M., Schoenmakers, T., \& Mheen, D. (2012). Treating internet addiction with cognitivebehavioral therapy: A thematic analysis of the experiences of therapists. International Journal of Mental Health \& Addiction, 10, 69-82. doi:10.1007/s11469-010-9295-0

Sullivan, D. K., Goetz, J. R., Gibson, C. A., Washburn, R. A., Smith, B. K., Lee, J., . . Donnelly, J. E. (2013). Improving weight maintenance using virtual reality (second life). Journal of Nutrition Education and Behavior, 45, 264-268. doi:10.1016/j.jneb.2012.10.007

Yee, N. (2006a). The demographics, motivations, and derived experiences of users of massively multi-user online graphical environments. Presence: Teleoperators and Virtual Environments, 15, 309-329.

Yee, N. (2006b). Motivations for play in online games. CyberPsychology \& Behavior, 9, 772-775. doi:10.1089/cpb.2006.9.772

Young, K. S. (2011). CBT-IA: The first treatment model for Internet addiction. Journal of Cognitive Psychotherapy, 25, 304-312. doi:10.1891/0889-8391.25.4.304

\section{Author Biographies}

Lori D. Franklin, MSW, LCSW is a clinical associate professor in the Anne and Henry Zarrow School of Social Work at the University of Oklahoma. Her clinical experience includes work with adults with mental illnesses and adult survivors of childhood abuse.

Scott A. Swan, MA, PhD currently works with the Veterans Health Administration treating adult veterans suffering from combat stress, depression, military sexual trauma, developmental transitions and chemical dependence. He is part time faculty in clinical psychology at the University of Tennessee. 